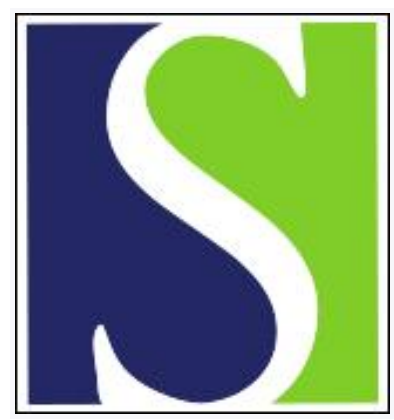

Scand J Work Environ Health 2006;32(6):502-514

https://doi.org/10.5271/sjweh.1055

Issue date: 31 Dec 2006

\title{
Workhours in relation to work stress, recovery and health
}

by Härmä $M$

Affiliation: Finnish Institute of Occupational Health, Centre of Expertise on Human Factors at Work, Topeliuksenkatu 41 a A, Fl-00250 Helsinki, Finland. Mikko.Harma@ttl.fi

Refers to the following texts of the Journal: 2006;32(6):482-492 2005;31(3):179-183 1999;25(2):85-99 2006;32(3):232-240 2005;31(5):329-335 1997;23(6):403-413 2003;29(3):171-188 1999;25(4):376-381 1998;24 suppl 3:141-145 2001;27(2):97-105 1997;23(4):257-265 2006;32(6):431-442 1998;24 suppl 3:13-17 2006;32(6):493-501 2006;32(6):421-430 2001;27(2):87-96 1998;24(4):300-307 2004;30(2):149-156 2003;29(6):444-451 2006;32(4):318-327 2003;29(1):27-34 2003;29(5):325-327 $1999 ; 25(6): 610-615$

The following articles refer to this text: $2006 ; 32(6): 413-419$; 2008;34(1):1-3; 2008;34(1):5-22; 2008;34(3):213-223; 2008;34(3):198-205; SJWEH Supplements 2008;(5):14-21; 2008;34(5):323-325; 2009;35(3):157-161; 2010;36(2):96-108; 2010;36(2):81-84; 2010;36(2):180-182; 2011;37(5):418-426; 2012;38(3):238-246; 2012;38(4):349-357; 2012;38(4):299-313; 2012;38(4):291-297; 2012;38(4):327-336; 2013;39(6):531-533; 2015;41(3):268-279; 2015;41(4):413-416; 2015;41(4):347-355; 2017;43(2):109-116; 2018;44(4):403-413; 2020;46(5):469-479; $2021 ; 47(8): 619-627 ; 2022 ; 48(1): 31-40$

Key terms: coronary heart disease; health; recovery; review; shift work; sleep; work stress; workhours

This article in PubMed: www.ncbi.nlm.nih.gov/pubmed/17173206

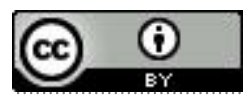




\title{
Workhours in relation to work stress, recovery and health
}

\author{
by Mikko Härmä, $M D^{1}$
}

\begin{abstract}
Härmä M. Workhours in relation to work stress, recovery and health. Scand J Work Environ Health 2006;32(6, special issue):502-514.

This paper aims at describing the associations between workhours and psychosocial work characteristics and reviews the health effects of workhours and the related pathways. The role of insufficient sleep as a possible common pathway from workhours and work stress to cardiovascular illness is discussed. Finally, the key possibilities for improving recovery and health through changes in workhours are identified. Night work and shift work are related to a wide range of health effects, the evidence for the risk of cardiovascular morbidity being the strongest. Insufficient or poor sleep, related to insufficient recovery, can be a common pathway from long workhours, shift work, and work stress to cardiovascular illness. The most promising worktime-related means for decreasing the psychosocial workload and negative health effects of workhours would be (i) to regulate overtime and excessive workhours, (ii) increase individual worktime control, and (iii) increase recovery from the introduction of sleep-promoting principles into shift rotation.
\end{abstract}

Key terms coronary heart disease; recovery; review; shift work; sleep.

The changes that have occurred in the economy and in information and communication technology have increased the speed of business processes and strengthened the birth of the "24-hour society". As a result, occupational stress has become a major problem in modern work organizations (1). Especially, the significance of time and time-related activities in worklife has increased. Work can be done at any time and at any place. In some sectors, the need to compete with time has made workdays longer, while the time left for recovery has shortened. Work has become more intense and fastpaced (2), and, therefore, often results in insufficient time within a workday. Due to the discrepancy between the time available and the time needed, individual needs to control and balance time have become obvious. In consequence, there is an urgent need for tools that can alleviate the health impairments related to work stress (3).

The relationship between workhour characteristics and psychosocial work characteristics and job stress models is a controversial issue. Unfavorable workhours and occupational stress create similar psychophysiologi- cal stress reactions and long-term health effects, the indication being common pathways from work to health. In this paper, I try to answer the following questions: (i) what are the general trends in workhours, (ii) what are the associations between workhours and psychosocial work characteristics, (iii) what are the health effects of long workhours and shift work, (iv) what are the pathways from long workhours and shift work to health, (v) is insufficient or poor sleep a common pathway from long workhours, shift work, and work stress to cardiovascular illness, and (vi) what are the key possibilities for improving recovery and health through changes in workhours?

This paper tries to sketch an overall picture of the relationship between workhours, psychosocial work characteristics, recovery, and health, but it does not review the area in detail. Sleep is closely related to stress (4). Since sleep problems form a common problem related to unfavorable psychosocial work demands, shift work, and long workhours, the role of sleep and insufficient recovery as a possible pathway from work to illness is discussed in more detail. 


\section{Trends in workhours}

Although there is some controversy about the detailed trends in workhours $(5,6)$, it is obvious that worktime patterns are becoming more diversified, flexible, irregular, and sometimes unhealthy (7).

Company-based flexibility in workhours refers to the needs of employers to extend, modify, or reduce workhours according to client and production needs (8). Shift work and paid overtime, as well as part-time and weekend work, are common forms of company-based flexibility. While company- and customer-oriented flexibility has clearly been on the rise, optional overtime has also become common in many countries due to the increased commitment and independence of skilled workers (5). In addition to the trends in company-based flexibility, individual flexibility in workhours and employee worktime control has also become common (810). Unlike company-based flexibility in worktime, individual flexibility meets the needs of employees, providing them with autonomy regarding, for example, starting and ending times, breaks, days off, vacations, and the number of workhours (8). Employee worktime control is close to individual flexibility and can be defined as an employee's possibilities to control the duration, position, and distribution of his or her worktime, that is, autonomy with regard to worktime (9). In a representative survey of Finnish men and women in 2000, $71 \%$ of all of the employees had at least one type of company-based flexibility, while $31 \%$ had some form of individual flexibility in their worktime (10).

Trends in average workhours vary according to economic areas, but there is some evidence indicating a polarization of average workhours in relation to the lengthening of workhours among white-collar workers and the shortening of workhours in blue-collar work. In the long run, the average number of paid workhours has decreased in most countries belonging to the Organization for Economic Cooperation and Development (OECD). In Europe, $17 \%$ of employees had night or shift work in 2000, 29\% worked continuously under tight deadlines, and $20 \%$ did 45 or more hours of work in a week (2). About $13 \%$ of the full-timers worked 51 hours or more in a week, the number of hours being clearly higher than the 48-hour "maximum limit" established by the European Directive on Working Time (2). In addition to the actual workhours, surveys in the European Union (EU) have gathered information on the desired number of workhours (11). The average preferences in Europe converge between 30 and 40 hours a week and indicate a deep gap between the desired and actual length of the workweek. In summary, both company and individual flexibility in workhours has increased, making workhours more diverse. Average workhours have decreased, but unpaid overtime has be- come typical among many workers. Needs for worktime control and lower average workhours have prevailed.

\section{Associations between workhours and psychosocial work characteristics}

In this issue of the Scandinavian Journal of Work, Environment \& Health, a systematic review and metaanalysis by Kivimäki et al (12) shows that work stress, defined by three prevalent work stress models, is associated with a $50 \%$ excess of coronary heart disease (CHD) according to prospective studies. Since also long workhours, shift work, and employee worktime control are associated with stress-related diseases, the conceptual associations between work stress and workhours are important.

The term psychosocial factor has been defined as a measurement that potentially relates psychological phenomena to the social environment and to pathophysiological changes (13). Psychosocial factors at work have been studied with work stress theories that try to describe conceptualized factors that are likely to elicit harmful stress reactions at work. Kompier (14) made a comparative overview of the most central work stress models to identify the critical job features of the seven most common work stress theories. He found a remarkable overlap between the theories. The most frequently used features in the different theories were job demands, autonomy, skill variety, and social support. Factors less frequently included were feedback, task identity, job future ambiguity, and pay. In this paper, work stress refers to the potentially harmful combinations of the conceptualized psychosocial factors at work.

The most well-known work stress model, the jobstrain model, suggests that job control modifies the potentially adverse health effects of job demands (15). A job with high demands and low control over job content is called high-strain work, which, in the long run, increases the risk of stress-related diseases. High demands buffered by high control results in an active job, promoting individual growth, resources, and health. In the job-strain model, the job-demand factor primarily measures job speed and quantity, including also an item focusing directly on the appraisal of having sufficient time for the job. It can be hypothesized that time pressure at work has a negative impact on the number and length of workbreaks (internal recovery), and it induces overtime due to the imbalance between workload and time for work. Overtime is more common in jobs characterized by high job demands (16-18), and the job-demand factor correlates with overtime, especially with structural overtime (18). 
Karasek's job-control factor does not include worktime control or control over work scheduling. Perceived control over workhours still correlates highly with the job control factor (19). The operationalization of the control factor has actually been criticized in that too narrow a spectrum of control has been applied, covering only control elements intrinsic to work and ruling out the home-work balance (20). Furthermore, Ganster (20) has listed the possible important dimensions of control as follows: control over worktasks (choice, order, quality, or quantity of output), pacing and breaks, schedules (workhours, vacations, and shifts), the physical environment, organizational policies, other people, mobility, and information (predictability). Among white-collar workers, overtime is associated with higher decision latitude and greater possibilities to influence the work situation (17). Shift workers have shorter weekly workhours, and they experience lower control over their job when compared with day workers, while work demands and social support do not differ (21-23).

The second common work-stress model, the effortreward imbalance model of Siegrist et al (24) focuses on a person's perception of the balance of his or her efforts at work with rewards received. The extrinsic component of the effort-reward imbalance model postulates that a longitudinal imbalance is followed by health problems, while over-commitment should be especially problematic for the intrinsic component. The different aspects of workhours are not directly covered by the effort-reward imbalance model, but it can be hypothesized that overtime could be an indicator of overcommitment. Similarly, having control over workhours and a good home-work balance could be viewed as rewarding elements of work (25-27).

Neither the job-strain model nor the effort-reward imbalance model directly considers the possibilities for recovery after work. Since workhours are directly related to the daily and weekly time budgets and time left for family, other social activity, and sleep, the recovery aspect could be especially relevant in explaining the health effects of unfavorable workhours. According to this need, a third major stress model, the effort-recovery model, suggests that the possible negative consequences for long workhours on health depend on the possibilities for recovery during the day (internal recovery) and after work (external recovery) (28).

In summary, workhours are closely related to the three major work-stress models. Overtime is often related to high work demands and greater possibilities to influence the work situation. Overtime can be an indicator of overcommitment in the effort-reward imbalance model, and high worktime control is associated with better autonomy at work. Shift work is related to lower job control, but not to differences in work demands.

\section{Workhours and health}

\section{Long workhours}

Two recent reviews indicate that there is growing evidence that overtime and extended workdays are associated with cardiovascular disease, self-rated health problems, and fatigue $(29,30)$. Working more than 11 hours a day, compared with a normal workday, was found to be associated with a three times higher risk for myocardial infarction (31) and about a four times higher risk for noninsulin-dependent diabetes (32). Working 60 hours or more a week was also associated with a higher risk (relative risk $=3.7$ ) of disability retirement (33). On the other hand, studies related to the incidence of type II diabetes show more contradictory results (31, 34).

Recent epidemiologic evidence shows that both daily and weekly workhours are directly related to an increase in the rate of occupational accidents and injuries and that the relation is not dependent on age, gender, occupation, or the sector of industry (35-37). An analysis of aggregated data showed an exponential increase of accident risk from 8 up to 16 hours at work. (35). According to Dembe et al (36), working in jobs with overtime schedules is associated with a $61 \%$ higher injury hazard rate than jobs without overtime, and working at least 12 hours a day is associated with a $23 \%$ hazard rate. Long workhours are also related to a higher risk of motor vehicle accidents. For example, prospective data on interns in the United States showed an odds ratio of 2.3 for motor vehicle crashes after an extended workshift when compared with a shift of normal length (38).

Long workhours can contribute to the "double burden" of full-time and domestic work. In a prospective cohort study among 25703 full-time public-sector municipal employees for whom future absence records were linked to the survey data, men and women experiencing severe work-family spillover had a 1.5-1.6 times higher rate of sickness absence and a 3.6-6.5 times higher odds ratio for psychological distress and poor health than those with no such experience (39). Indeed, while long paid workhours alone were associated with even lower self-certified ( $\leq 3$ days) and medically certified ( $>3$ days) sickness absences among municipal employees, total workhours (paid plus domestic workhours like cleaning, washing, etc) were associated with higher sickness absences (40). Long paid workhours thus did not predict increases in sickness absences alone, but, when combined with long domestic or commuting workhours, the relationship was clear. In summary, there is evidence that continuously worked long hours (like 50 hours or more a week) or long total workhours (work + home) are associated with objective and self-rated health problems, sickness absences, and fatigue. However, 
workhours may not be an independent predictor of health.

\section{Shift work}

Shift work is related to a higher risk of sleep disorders, fatigue, and occupational accidents. In the long run, shift work has been shown to increase the risk of cardiovascular and gastrointestinal diseases but may also increase the risk of breast cancer, type II diabetes, and disturbances in pregnancy outcome $(41,42)$.

According to DSM-IV clinical criteria, $10 \%$ of night and rotating shift workers have what is called the shiftwork sleep disorder $(43,44)$. Among shift workers, night sleep before the early morning shifts and day sleep after night shifts are normally curtailed by 2 hours. [See, for example, the papers by Sallinen et al (45), Bonnefond et al (46), and Rosa et al (47).] Sleep loss involves mainly stage-2 and rapid-eye-movement sleep. Similarly, sleepiness is the most frequent during the night and early morning shifts $(42,48)$. For example, severe sleepiness was reported for $49 \%$ of the workers on night shifts and for $20 \%$ of those on early morning shifts in a large group of locomotive engineers (48). The odds ratios showed that the risk for severe sleepiness was 6-14 times higher on the night shift and about twice as high on the morning shift as on the day shift.

Apparently due to occasional sleepiness, shift work is associated with the risk of occupational injuries (49, 50). Recently, the effects of nonstandard shift schedules on occupational accidents in more than 100000 job records were analyzed in a follow-up study covering 13 years (49). After control for age, gender, occupation, industry, and region, the calculated hazard ratio was 1.43 for evening shifts, 1.36 for rotating shifts, and 1.30 for night shifts.

According to a review of 13 longitudinal and 4 casereferent studies and a later meta-analysis including an additional negative study, shift work increases the risk of CHD by $30-40 \%$ even when other traditional risk factors and social class are controlled for $(21,27,51-$ 57). A later cessation of shiftwork exposure decreases the risk. A recent 13-year follow-up study showed that the relative risk in the 5-year follow-up for shift work was 1.59 , while in the 13-year follow-up with more retired workers, it decreased to 1.34 (54). There is also some evidence that night and shift work may have an impact on the metabolic syndrome $(58,59)$ and type II diabetes (60). A meta-analysis on breast cancer gave an aggregated estimate of an increased risk of 1.48 for night shift workers when compared with day workers (61). In earlier studies, shift work was found to be related to peptic ulcer (62) and disturbances in pregnancy outcome, indicated as low birthweight $(63,64)$ and preterm birth $(65,66)$.
In conclusion, night and shift work is currently a remarkable occupational health problem. The individual risk and odds ratios for specific diseases due to shift work are relatively low, mostly under 2 . Since both exposure and many of the outcomes are still common (the incidence of shift work is about $20 \%$ and the outcomes include diseases like CHD, type II diabetes, and breast cancer), the overall significance of night and shift work as an occupational risk factor is high.

\section{Pathways from long workhours and shift work to health}

\section{Long workhours}

The review of van der Hulst (29) examined the validity of two different pathways, insufficient recovery and poor lifestyle, in the relationship between long workhours and adverse health. The evidence on cardiovascular physiological pathways proved to be weak with only few studies indicating that extended workhours could be related to, for example, increased heart rate and blood pressure. Some occasional evidence was found for the relationship between long workhours and the depression of the immunological system. No evidence was found for a possible association between long workhours and poor eating habits or physical inactivity. The most consistent pathways from long workhours to health were related to an inverse association between long workhours and sleep (29).

In this issue of the Scandinavian Journal of Work, Environment \& Health, a new review shows that incomplete recovery is an important pathway to chronic health impairment (67). As well recognized, long workhours and overtime are associated with reduced time for recovery and difficulties to unwind after work (68). Although there is no direct relationship between the length of the workweek and daily sleep, very short sleep (6 hours or less) is related to longer weekly workhours than midrange (over 6 but less than 9 hours) or long sleep (9 hours or more) in the general population (69). Excessive workhours (50 hours or more) are related to shortened sleep (70-72) but not to insomnia $(71,72)$.

The relationship between long workhours and health is also dependent on work demands. In a recent study, overtime was associated with a higher need for recovery only for the employees who experienced high job demands according to the job-strain model (18). In summary, the most consistent pathway from long workhours to health proceeds through decreased recovery and insufficient sleep. Long workhours are still reflected in reduced sleep and insufficient recovery only among those with excessive workhours or high work demands. 


\section{Shift work}

Whether shift work is an independent risk factor for health has often been questioned. Since shift work is associated with social class, it could only be a proxy for other differences in the work environment, changes in lifestyle, or, for example, differences in long-term selection into different occupations. Apart from social class and differences in work and the work environment (23), the most probable pathways from shift work to ill health are changes in lifestyle, a mismatch between circadian rhythms, and shift workers' stress due to a disturbed social life (41).

The strong inverse gradient between social class and CHD is well known. [See, for example, the papers by Bøggild et al (23), Marmot (73), and Hein et al (74).] Two- and three-shift workers are, on the average, less educated than permanent day workers, even in the same companies. Due to differences in worktasks and occupations, shift workers more often have higher exposure than day workers to low decision latitude, job insecurity, conflicts at work, repetitive and cognitively demanding tasks, noise, and physical workload, some of which have been found to be related also to the risk of heart disease (23). The work demands of some shift worker occupations may also be especially stressful due to the special nature of the work (eg, on-call emergency work and working alone). For example, $68 \%$ of a representative group of anesthetists reported stress, and $18 \%$ had moderate burnout (75). Being frequently oncall had a dose-response type relationship to the existence of stress symptoms, burnout, and feelings of exhaustion.

Some prospective studies showing a relationship between shift work and CHD controlled for social class (52-56). A high demand-low control work situation, like that of effort-reward imbalance, may also partly mediate the association between shift work and cardiovascular risk; for example, the prevalence odds ratios for hypertension and atherogenic lipids attributable to effort-reward imbalance were relatively the highest among shift workers as compared with daytime workers (27). There is evidence that shift work is an independent risk factor for CHD in relation to some physical work environment factors like noise and physical workload. In a recent follow-up study, the risk estimates for shift work varied from 1.62 to 1.22 , depending on the length of the follow-up, the reference group, or adjusted factors (54).

Shift workers have somewhat more unhealthy living habits than day workers, a characteristic also associated with observed differences in socioeconomic class. Shift work is especially related to increased smoking $(51,52,76)$, higher triglyceride levels, and lower levels of high-density lipoprotein (HDL) cholesterol (77-79), and an increased risk of weight gain and obesity (53,
$76,80)$. On the other hand, there is negative or inconclusive evidence for the relationship of shift work to blood pressure, blood lipids, physical inactivity and energy, protein, total fat, and carbohydrate intake.

It is not clear whether epidemiologic studies on the relationship between shift work and health should control for factors like smoking and obesity. Because working in shifts seems to increase smoking and weight gain, these factors could also be handled as mediating rather than confounding factors. In any case, changes in lifestyle factors do not seem to explain the increased risk related to CHD, as shown by most of the previously mentioned prospective studies. However, the joint effects of shift work and adverse lifestyle factors on CHD seem to be multiplicative (76).

The specific pathway from shift work to ill health, especially to CHD, may be circadian disturbance, causing the shiftwork sleep disorder and a disruption of the circadian rhythms of many nutritional, cardiovascular, immunological, or metabolic functions. The regulation of sleep-wakefulness at work has been studied extensively, and the circadian rhythms in sleep and sleepiness are well acknowledged. Circadian rhythmicity regulates the ability to fall asleep, time spent awake during sleep, sleep length, and sleep structure (81). Besides the time of the day, sleepiness is modified by the time spent awake. Basically, sleepiness at work grows exponentially by the total time spent awake, while the time of day simultaneously modifies sleepiness by a sinusoidal pattern (81).

The manifestation of sleep and sleepiness in abnormal workhours is highly individual (82). The percentage of the working population that fails to adjust to shift work is usually estimated as being approximately 10 $20 \%$. Aging is one of the major factors influencing both the circadian adjustment to night work (83) and the homeostatic functions of sleep (84). Aging is related to slower circadian adjustment during consecutive nightshifts, as well as to shorter sleep after nightshifts $(44,45)$. Epidemiologic studies indicate that insomnia due to shift work increases with age $(85,86)$. However, older shift workers do not complain about more sleepiness than their younger colleagues $(46,47)$. Diurnal type, personality, and different coping mechanisms (like physical activity) modify the effects of night and shift work on sleep and fatigue $(82,87)$. For example, it is more difficult for morning types, with an earlier circadian phase and sleep-wake rhythm, to phase delay their circadian rhythms during consecutive night shifts than it is for evening types (82). In a controlled intervention study, regular physical activity improved sleep in general, and alertness especially, during night shifts among nurses on an irregular shift schedule (87).

The disruption of circadian rhythms may entail several pathways to $\mathrm{CHD}$, some of them also not involving 
sleep. Many of the changes can trigger short-term stress reactions and mechanisms that increase the clinical manifestations of cardiovascular disease. The frequency of ventricular extrasystoles increased by $49 \%$ among shift workers during the first year of shift work in a prospective study of new shift workers, the increase being significantly higher than for the daytime workers (88). Differences in the circadian timing of meals among shift workers have also been shown to influence postprandial levels of lipids and glucose $(89,90)$. Insufficient sleep activates the sympathetic nervous system and leads to increases in blood pressure and heart rate $(91,92)$. Only six successive nights of time in bed restricted to 4 hours per night increased the activity of the sympathetic nervous system, increased evening cortisol concentrations, and decreased glucose tolerance among young healthy persons. On the other hand, sleep deprivation increases hunger and decreases leptin, a factor inhibiting hunger $(93,94)$. Experimental short-term sleep deprivation also increases the peripheral circulation of leukocytes, interleukins, and C-reactive protein, the lastmentioned being a predictor of the risk of stroke and myocardial infarction $(95,96)$.

In conclusion, the literature indicates several pathways from shift work to poor health. Disturbed sleep and increased sleepiness are probable reasons for a higher risk of accidents. Shift work is related to a lower socioeconomic class and other risks in the work environment. Shift workers are also more often obese, smoke more, and have higher triglyceride levels and lower levels of HDL cholesterol. The disruption of the circadian rhythms and insufficient sleep can still trigger independent physiological, metabolic, and endocrinological changes leading to obesity, cardiovascular and gastrointestinal diseases, and breast cancer.

\section{Insufficient or poor sleep-a common pathway from long workhours, shift work, and work stress to car- diovascular illness?}

It is tempting to suggest that short or disturbed sleep, related to insufficient recovery $(96,98)$, could be a common pathway connecting both night and shift work, extended workhours, and work stress to adverse cardiovascular health (98). Excessive workhours and overtime are related to shortened sleep (69-71) and a greater need for recovery (18). Similarly, shift work $(46-48,55,85$, 86 ) is closely tied to shortened or disturbed sleep, as shown before, and with the need for recovery $(99,100)$. Work stress is also related to insufficient recovery (18), and poor sleep is one of the most typical symptoms of psychological stress reactions. Work demands and control, based on the job-strain model, have a strong crosssectional relationship to insomnia, sleep deprivation, and daytime fatigue independent of workhours and lifestyle factors like physical activity, smoking, and alcohol consumption $(101,102)$. For example, in a survey of middle-aged men (101), $30.3 \%$ of the men with job strain had insomnia, whereas only $5.3 \%$ of those with both low demands and high decision latitude had the same problem. Even a single-item measure of psychological stress including disturbed sleep as the main symptom of work-related stress reactions showed satisfactory validity as a general measure of psychological stress (103).

A high need for recovery $(104,105)$, short sleep (46 hours a day), and insomnia (106-108) have all been shown to increase the risk for CHD in large prospective studies. In a recent prospective cohort study with a 26-year follow-up, the perception of insufficient recovery during free weekends had an elevated risk for cardiovascular death, whereas other causes of mortality after adjustment for age, gender, and 16 conventional risk factors, including depressive symptoms, fatigue, and work stress, did not (105). Short sleep (6 hours or less) and insomnia (difficulties falling asleep or waking up during the night) are also related to the risk of obesity and type II diabetes (108-111). Sleep disturbances are a good indicator of future health problems and delayed recovery after stressful events. In a recent study, the timing of stressful events (self-reports of a family death or illness) and the duration and quality of postevent sleep were linked with monthly sickness absence records in a large group of city employees (112). The findings showed that a long-term increase in sickness absence, indicating delayed recovery, is particularly likely if the stressful event is associated with sleep disturbances after the event. In conclusion, the evidence suggests that short or disturbed sleep could be a common pathway connecting night work, shift work, extended workhours, and work stress to cardiovascular illness. However, sleep can, but need not be the only pathway between workhours, the psychosocial work environment, and health.

\section{Possibilities to improve recovery and health through the redesign of workhours}

Since shift work and long workhours can result in poor health, it would be important to know what types of modifications or improvements in workhours are needed to decrease the psychosocial workload and the health effects of workhours. Unfortunately, there is a lack of controlled intervention studies testing the possibilities of improving health through changes in workhours. Since workhours are the most closely related to job demands (overtime), autonomy or control (worktime control), and the concept of recovery (sleep), worktime 
research focusing mainly on the effect of workhours on these three areas is briefly reviewed.

\section{Regulation of overtime and excessive workhours}

Overtime and excessive workhours are controlled by legislation in many countries. In Europe, the EU directive 93/104 on workhours calls for a maximum of 48 hours of work per week. However, in some countries, there is a possibility for "opting out", meaning that agreements between social partners may circumvent the directive.

Although epidemiologic studies indicate that overtime and extended workdays are associated with impaired health (29) and accidents (36-38), there is sparse evidence that a decrease in the average number of workhours improves health. Those who work overtime are often in a position with high demands, but also with high decision latitude (16-18). The literature on the preference of 8- or 12-hour workshifts does not provide an answer to the problem of possible long-term effects from excessive workhours, since the longer shifts are not reflected as longer average worktime due to extra days off. In fact, the need to decrease overtime, in addition to employee initiatives, is often a starting point for negotiations in many companies with respect to changing from 8- to 12-hour shifts (113).

Very few studies have manipulated overtime experimentally. Recently, the effects of overtime on stress reactions were studied by comparing a week of overtime with a normal week within the same group while controlling for workload (114). The results showed that the week with overtime was associated with decreased sleep, more symptoms of fatigue and exhaustion, and an increase in sleepiness at the end of the week. There are some company-based interventions that have studied the effects of a reduction in workhours from 7 or more to 6 hours (115-117). In an intervention study among female health care workers, a decrease in workhours (to a 6-hour workday) resulted in improvements in the social life of the workers and in moderate improvements in well-being when the group was compared with a reference group with no changes in workhours (117). In another study, a shift to 6-hour workdays was followed by a reduction of neck-shoulder and back pain in three separate organizations when fulltime payment of the workers was retained (115). According to Anttila (116), the benefits of shorter workhours were the most apparent in regard to social life, but they also introduced some positive effects on the perceived stress of the workers.

In practice, the regulation of overtime is dependent on management values and practice. Countermeasures against a fast workpace should not only include methods to increase work efficiency through time management, the use of new technology, and learning, but should also encompass priority setting and control for reasonable time budgets (118). The length of actual worktime is also dependent on the frequency and duration of workbreaks. Several studies have tried to discover the optimal duration, frequency, and type for rest breaks that reduce job-related strain. Studies made mainly in industry indicate that the use of rest breaks leads to less strain and injury (119). There is also evidence that rest breaks affect accident risk favorably (120). In summary, information is lacking on strategies to control overtime and excessive workhours and their health effects, while transfer from a normal workweek to a 6-hour day is related to favorable changes in subjective health and social life. The use of regular rest breaks during work is inversely related to the risk of injury and accidents.

\section{Individual worktime control}

In Finland, 39\% of men and 29\% of women were able to regulate their personal workhours (flexitime or time banking), according to a representative survey of wage and salary earners in 2000 (10). At the cross-sectional level, higher individual worktime control was related to less mental stress and distress due to conflicts in combining workplace and family roles (10). Poor employee control over worktimes was also found to be related to a decrease in subjective health and an increase in sickness absences among women even when potential confounders like job control were adjusted for (121). In a prospective setting, women with a low level of worktime control had a 1.9 times higher odds ratio for poor selfrated health, a 1.4 times higher odds ratio for psychological distress, and a 1.5 times higher risk of medically certified sickness absences than women with a high level of worktime control (121). The same group also examined whether the effects of work stress (according to both the job-strain and effort-reward imbalance models) on sickness absence depend on worktime control (122). The results showed that good control over worktime reduced the adverse effect of work stress on sickness absences, especially among female employees. In addition, good worktime control was associated with less negative effects of long total workhours (work + home) on subjective health and future sickness absences (40).

In a 6-month before-after study in six maternity wards, the effect of improved individual worktime control on the perceived health of hospital midwives was studied (123). As a result of the intervention, work strain and perceived stress decreased, the most obvious changes taking place among the elderly midwives. In another study, the use of self-selected worktimes through individual planning and the use of a time bank (a system supporting a more-flexible handling of overtime) was studied (124). Although the change in 
workhours decreased the number of employees, self-selected workhours increased the employees' satisfaction with their workhours. In conclusion, there is considerable evidence that worktime control is a powerful tool that can be used to help improve both social life and health and alleviate the negative effects of long total workhours on health.

\section{Increased recovery from the introduction of sleep- promoting principles into shift rotation}

In shift work, shift schedules vary significantly in relation to how they offer time for recovery in relation to different shifts. If the time-off between shifts is less or even close to the average sleep need ( 7.5 hours), full recovery is not possible. The use of "quick returns", in other words, the existence of a short time-off between evening and morning shifts, is frequent in many shift systems. Quick returns are related to shortened sleep (45). On the other hand, the length of the shift worker's sleep is inversely related to the occurrence of severe sleepiness during shifts (48). A later starting time in the morning shift is important for the length of the previous night's sleep. A controlled intervention study on a regular shift system indicated that a delay in the shift starting time resulted in an improvement in both sleep and wakefulness before the morning shift (47). In an irregular shift system, each hour of delay in the starting time of the morning shift was related to a 40- to 50minute extension of the main sleep length (45).

About 50-80\% of shift workers nap before the first night shift $(45,125)$. Napping before and during night shifts cuts the time spent awake, and even short periods of sleep improve alertness and performance considerably $(45,126)$. Too short a time-off interval or an early starting time for a night shift makes napping before the night shift difficult. The later the starting time of a night shift, the greater the likelihood of napping (45).

The speed and direction of shift rotation, as well as the distribution of free days within the shift system, are relevant in relation to recovery and health. There is some evidence that improvements in shift scheduling can decrease the risk factors of heart disease $(79,127)$. Increased ergonomic scheduling with a more regular and predictable shift schedule was found to be associated with favorable changes in triglyceride and HDL cholesterol levels (79). The observed changes in the biomarkers were not related to changes in smoking, alcohol consumption, or exercise at baseline. However, possible changes in diet were not measured. The use of forward-rotating shift systems seems to be favorable with respect to the sleep, social life, and family life of workers $(100,128-132)$. For example, as compared with forward-rotating schedules, backward rotating shift systems showed a relative risk of 2.9 for an increased need for recovery and a risk of 3.2 for poor general health (100).

Many recommendations suggest the use of rapid forward-rotating shift systems (only 1-3 consecutive night shifts) instead of weekly rotating schedules in order to optimize recovery and disturbances in social life within the shift system $(128,129,133)$. The human circadian system is rigid, but it tries to adjust to a change in shift rotation. In slowly rotating shift systems, more circadian adjustment (mostly by phase delay) may take place than in rapidly rotating shift systems (134). Without exposure to bright light, rapid adjustment still occurs only among $30-50 \%$ of shift workers $(134,135)$. Even if rapid adjustment takes place, time is again needed for re-adjustment after the end of successive night shifts. Consecutive night shifts are thus often related to sleep deprivation. The risk of accidents has also been shown to correlate with the number of consecutive night shifts in a shift system (136).

The possible benefits of a rapidly rotating shift system have been studied in few intervention studies (130, 131, 137). Recently, the possible benefits of a very rapid forward-rotating shift system in relation to age were studied in a controlled intervention study (131). The use of the new shift schedule increased the main sleep length after the night shifts and improved alertness and psychomotor performance in relation to the night shift among the older (over 45 years) age group. Alertness improved during free time after the night shifts, and sleep complaints decreased after all of the shifts. The shift workers also reported a marked improvement in general health and social and family life during the new shift system.

In conclusion, circadian adjustment to night work in rotating shifts systems may not be desirable, and the choice of especially rapid forward-rotating shift systems seems to give the fastest recovery in relation to both sleep-wakefulness and the possibilities to utilize the days off after night shifts in social and family life. In irregular shift systems, the avoidance of quick returns and early morning and night shifts are related to longer night sleep and improved possibilities for daytime napping.

\section{Needs for future research}

It seems that the literature on work stress has often neglected to analyze the characteristics of specific workhours as a determinant of work stress and, therefore, has missed the possibilities for making practical recommendations and detailed analyses of the sources of ill health in relation to work stress. Research on workhours, on the other hand, has lacked theoretical and conceptual contexts, and the interpretation of some 
specific findings has, therefore, been difficult. In general, there is an urgent need for knowledge about tools that could alleviate the health impairments related to work stress (3). Solutions focused on workhours could be practical tools with which to improve occupational health and well-being and alleviate the harmful effects of work stress.

Workhours are closely related to psychosocial work characteristics, for example, work demands and autonomy. More information is still needed on the relationship between workhours, recovery, and sleep and different work-stress models. Night and shift work, long workhours, and work-stress give rise to analogous shortand long-term changes in psychophysiological stress reactions and long-term health. Information is lacking on the effects of extended workhours and shift work on the risk of different diseases, but especially we lack information on the effects of different improvements in workhours on health. Intervention studies and prospective epidemiologic research using both subjective and objective measures of health are needed. Epidemiologic studies should clarify the role of different shift rotation systems (like rapidly or slowly rotating shift systems, etc) on long-term health instead of only classifying workhours as either day or shift work.

Research on workhours should utilize the conceptual and theoretical achievements of work stress research. Future research is needed on the pathways from work stress and workhours to illness, the so-called "black box" of psychosocial stress research. Since there is a considerable amount of evidence showing that insomnia and insufficient recovery are related to work stress, shift work, and cardiovascular illness, especially the role of sleep disturbance as a possible pathway from work stress to illness, should be further investigated.

We need practical tools to alleviate the effects of work stress on health. A decrease in overtime and excessive workhours, the use of workbreaks, and an increase in individual worktime control may decrease work stress and prevent long-term illness. However, much more evidence is needed on the feasibility and effectiveness of different interventions in variable shift systems and branches of industry. Finally, the ability to sustain sleep deprivation and stress are surprisingly individual. Therefore, studies on the reasons for individual differences in the tolerance to sustain stressful workhours and the possibilities to predict them are needed.

\section{References}

1. Kompier M. New systems of work organization and workers health. Scand J Work Environ Health. 2006;32(6, special issue):421-30.
2. Pascal P, Damien M. Third European survey on working conditions 2000. Luxemburg: European Foundation for the Improvement of Living and Working Conditions; 2001.

3. European Commission, Employment and Social Affairs. Guidance on work-related stress. spice of life or kiss of death? Luxemburg: Office for Official Publications of the European Communities; 2002. p 9-11.

4. Åkerstedt T. Psychosocial stress and impaired sleep. Scand J Work Environ Health. 2006;32(6, special issue):493-501

5. Åkerstedt T, Kecklund G. The future of workhours-the European view. Ind Health. 2006;43:80-4.

6. Organization for Economic Cooperation and Development (OECD). Employment outlook. Paris: OECD; 1998.

7. Figart D, Golden L. Understanding working time around the world: introduction and overview. In: Golden L, Figart D, editors. Working time: international trends, theory and policy perspectives. London: Routledge; 2000. p 1-17.

8. Costa G, Åkestedt T, Nachreiner F, Baltieri F, Folkard S, Frings Dresen M, et al. Flexible work hours, heath and wellbeing in the European Union: preliminary data from a SALTSA project. J Hum Ergol. 2001;30:27-33.

9. Knauth P. Innovative worktime arrangements. Scand J Work Environ Health. 1998;24 suppl 3:13-7.

10. Kandolin I, Härmä M, Toivanen M. Flexible workhours and well-being in Finland. J Hum Ergol. 2001;30:35-40.

11. Bielenski H, Bolch G, Wagner A. Working time preferences in sixteen European countries. Luxemburg: European Foundation for the Improvement of Living and Working Conditions; 2002.

12. Kivimäki M, Virtanen M, Elovainio M, Kouvonen A, Väänänen A, Vahtera J. Work stress in the etiology of coronary heart disease-a meta-analysis. Scand J Work Environ Health. 2006;32(6, special issue):431-42.

13. Hemingway H, Marmot M. Psychosocial factors in the aetiology and prognosis of coronary heart disease: systematic review of prospective cohort studies. BMJ. 1999;318:1460-7.

14. Kompier M. Dealing with workplace stress. In: Cooper C, editor. Handbook of stress medicine and health. Lancester (UK): CRC Press; 2005. p 349-74.

15. Karasek RA, Theorell T. Healthy work: stress, productivity and reconstruction of working life. New York (NY): Basic Books; 1990.

16. Beckers, D, van der Linden D, Smulders P, Kompier M, van Veldhoven M, van Yperen N. Working overtime hours: relations with fatigue, work motivation, and the quality of work. Occup Environ Med. 2004;46:1282-9.

17. Åkerstedt $\mathrm{T}$, Knutsson A, Westerholm $\mathrm{P}$, Theorell $\mathrm{T}$, Alfredsson L, Kecklund G. Mental fatigue, work and sleep. J Psychosom Res. 2004;57(5):415-6.

18. Van der Hulst M, Veldhoven M, Beckers D. Overtime and need for recovery to job demands and job control. J Occup Health. 2006;48:11-9.

19. Ala-Mursula, L, Vahtera J, Kivimäki M, Kevin M, Pentti J. Employee control over working times: associations with subjective health and sickness absences. J Epidemiol Community Health. 2002;56:272-8.

20. Ganster DC. Improving measures of worker control in occupational stress research. In: Hurrell JJ Jr, Murphy LR, Sauter SL, editors. Occupational stress: issues and developments in research. Philadelphia (PA): Taylor and Francis; 1988.

21. Tenkanen L, Sjöblom T, Kalimo R, Alikoski T, Härmä M. Shift work, occupation and coronary heart disease over 6 years of follow-up in the Helsinki Heart Study. Scand J Work Environ Health. 1997;23(4):257-65. 
22. Parkes K. Shiftwork, job type, and the work environment as joint predictors of health-related outcomes. J Occup Health Psychol. 1999;4:256-68.

23. Bøggild H, Burr H, Tüchsen F, Jeppesen HJ. Work environment of Danish shift and day workers. Scand J Work Environ Health. 2001;27(2):97-105.

24. Siegrist J, Peter R, Junge A, Cremer P, Seidel D. Low status control, high effort at work and ischemic heart disease: prospective evidence from blue-collar men. Soc Sci Med. 1990;31(10):1127-34.

25. Pisarski A, Bohle P, Callan VJ. Effect of coping strategies, social support and work-nonwork conflict on shift workers' health. Scand J Work Environ Health. 1998;24 suppl 3:141-5.

26. Pierce JL, Newstrom JW, Dunham RB, Barber AE. Alternative work schedules. Boston (MA): Allyn and Bacon; 1989. p 3-51.

27. Peter R, Alfredsson L, Knutsson A, Siegrist J, Westerholm P. Does a stressful psychosocial work environment mediate the effects of shift work on cardiovascular risk factors? Scand J Work Environ Health. 1999;25(4):376-81.

28. Meijman TF, Mulder G. Psychological aspects of workload. In: Drenth PJ, Thierry H, de Wolff CJ, editors. Handbook of work and organizational psychology. Hove (UK): Psychology Press; 1998.p 5-33.

29. van der Hulst, M. Long workhours and health. Scand J Work Environ Health. 2003;29(3):171-88.

30. Caruso CC, Hitchcock EM, Dick RB, Russo JM, Schmit JM. Overtime and extended work shifts: recent findings on illnesses, injuries, and health behaviors. Cincinnati (OH): US Department of Health and Human Services (DHHS), Centers for Disease Control and Prevention, National Institute for Occupational Safety and Health (NIOSH); 2004. DHHS (NIOSH) report no 2004-143.

31. Sokejima S, Kagamimori S. Working hours as a risk factor for acute myocardial infarction in Japan: case-control study. BMJ. 1998;317:775-80.

32. Kawakami N, Araki S, Takatsuka H, Shimazu H, Ishibashi H. Overtime, psychosocial working conditions, and occurrence of non-insulin dependent diabetes mellitus in Japanese men. J Epidemiol Community Health. 1999;53:359-63.

33. Krause N, Lynch J, Kaplan GA, Cohen RD, Goldberg DE, Salonen JT. Predictors of disability retirement. Scand J Work Environ Health. 1997;23(6):403-13.

34. Nakanishi N, Nishina K, Yoshida H, Matsuo Y, Nagano K, Nakamura K, et al. Hours of work and the risk of developing impaired fasting glucose or type 2 diabetes mellitus in Japanese male office workers. Occup Environ Med. 2001;58(9):569-74.

35. Nachreiner F. Time on task effects on safety. J Hum Ergol. 2001;30:97-201.

36. Dembe A, Erickson J, Delbos R, Banks S. The impact of overtime and long work hours on occupational injuries and illness: new evidence from the United States. Occup Environ Med. 2005;62:588-97.

37. Dong X. Long workhours, work scheduling and work-related injuries among construction workers in the United States. Scand J Work Environ Health. 2005;31(5):329-35.

38. Barger L, Cade B, Ayas N, Cronin J, Rosner B, Speizer F, et al. Extended work shifts and the risk of motor vehicle crashes among interns. N Engl J Med. 2005;13(2):125-34.

39. Väänänen A, Kevin M, Ala-Mursula L, Pentti J, Kivimäki M, Vahtera J. The double burden of and negative spillover between paid and domestic work: associations with health among men and women. Women Health. 2004;40(3):1-18.
40. Ala-Mursula L, Vahtera J, Kouvonen A, Väänänen A, Linna A, Pentti J, et al. Long hours in paid and domestic work and subsequent sickness absence: does control over daily work hours matter? Occup Environ Med. 2006;63:608-16.

41. Knutsson A. Health disorders of shift workers. Occup Med. 2003;53:103-8.

42. Åkerstedt T. Sleepiness as a consequence of shift work. Sleep. 1988:11;17-34.

43. Drake CL, Roehrs T, Richardson G, Walsh J, Roth T. Shift work sleep disorder: prevalence and consequences beyond that of symptomatic day workers. Sleep. 2004;27:1453-62.

44. Åkerstedt T. Shift work sleep disorder. Sleep. 2005:28;9-11.

45. Sallinen M, Härmä M, Mutanen P, Ranta R, Virkkala J, Müller K. Sleep-wake rhythm in an irregular shift system. J Sleep Res. 2003:12;103-12.

46. Bonnefond A, Härmä M, Hakola T, Sallinen M, Kandolin I, Virkkala J. Interaction of age with shift-related sleep-wakefulness, sleepiness, performance and social life. Exp Aging Res. 2006;32(2);185-208.

47. Rosa R, Härmä M, Pulli M, Mulder M, Näsman O. Rescheduling a three-shift system at a steel rolling mill: effects of a 1hour delay of shift starting times on sleep and alertness in younger and older workers. Occup Environ Med. 1996;53: 677-85.

48. Härmä M, Sallinen M, Ranta R, Mutanen P, Müller K. The effect of an irregular shift system on sleepiness at work in train drivers and railway traffic controllers. J Sleep Res. 2002;11:141-51.

49. Dembe AE, Erickson JB, Delbos RG, Banks SM. Nonstandard shift schedules and the risk of job-related injuries. Scand J Work Environ Health. 2006;32(3):232-40.

50. Smith L, Folkard S, Poole C. Increased injuries on night shift. Lancet. 1994; 344:1137-9.

51. Bøggild H, Knutsson A. Shift work, risk factors and cardiovascular disease [review]. Scand J Work Environ Health. 1999;25(2):85-99.

52. Boggild H, Knutsson A. Shift work and heart disease: metaanalysis of the epidemiological literature. In: Hornberger S, Knauth P, Costa G, Folkard S, editors. Shift work in the 21st Century. Frankfurt am Main: Peter Lang; 2000. p 189-94 (Arbeitswissenschaft in der betrieblichen Praxis; Bd.17).

53. Kawachi I, Colditz G, Stampfer M, Willett W, Manson J, Speizer E, et al. Prospective study of shift work and risk of coronary heart disease in women. Circulation. 1995; 92:317882.

54. Virkkunen H, Härmä M, Kauppinen T, Tenkanen L. The triad of occupational exposures to shift work, noise, and physical workload and risk of coronary heart disease. Occup Environ Med. 2006;63:608-16.

55. McNamee R, Binks K, Jones S. Faulkner D, Alovak A, Cherry NM. Shiftwork and mortality from ischaemic heart disease. Occup Environ Med. 1996;53:367-73.

56. Knutsson A, Hallquist J, Reutenwall C, Theorell T, Åkerstedt T. Shift work and myocardian infarction: a case-control study. Occup Environ Med. 1999;56:46-50.

57. Orth-Gomer K. International epidemiological evidence for a relationship between social support and cardiovascular disease. In: Shumaker SA, Czajkowski SM, editors. Social support and cardiovascular disease. New York (NY): Plenum Press; 1994. p 97-117.

58. Nagaya T, Yoshida H, Takahashi H, Kawai M. Markers of insulin resistance in day and shift workers aged 30-59 years. Int Arch Occup Environ Health. 2002;75:562-8.

59. Karlsson B, Knutsson A, Lindahl B, Alfrersson L. Metabolic 
disturbances in male workers with rotating three-shift work: results of the WOLF study. Int Arch Occup Environ Health. 2003;76:424-30.

60. Morikawa Y, Nakagawa H, Miura K, Soyama Y, Ishizaki M, Kido T, et al. Shift work and the risk of diabetes mellitus among Japanese male factory workers. Scand J Work Environ Health. 2005;31(3):179-83.

61. Megdal S, Kronke C, Laden F, Pukka E, Schernhammer E. Night work and breast cancer risk: a systematic review and meta-analysis. Eur J Cancer. 2005;41:2023-32.

62. Segawa K, Nakazawa S, Tsukamoto Y, Kutita Y, Goto H, Fukui A, et al. Peptic ulcer is prevalent among shift workers. Dig Dis Sci. 1987;32:449-53.

63. Armstrong B, Nolin A, MacDonald A. Work in pregnancy and birth weight for gestational age. $\mathrm{Br} \mathrm{J}$ Ind Med. 1989;46:196-9.

64. Xu X, Ding M, Li B, Christiani D. Association of rotating shift work with preterm births and low bright weight among never smoking women textile workers in China. Occup Environ Med. 1994;51:470-4.

65. MacDonald A, McDonald J, Armstrong B, Cherry N, Nolin A, Robert D. Premature and work in pregnancy. Br J Ind Med. 1988;45;56-62.

66. Axelsson G, Rylander R, Molin I. Outcome of pregnancy in relation to irregular and inconvenient work schedules. Br J Ind Med. 1989;46:393-8.

67. Geurts S, Sonnentag S. Recovery as an explanatory mechanism in the relation between acute stress reactions and chronic health impairment. Scand J Work Environ Health. 2006;32(6, special issue):482-492.

68. Rissler A. Stress reactions at work and after work during a period of quantitative overload. Ergonomics. 1977;20:13-6.

69. Kronholm E, Härmä M, Hublin C, Aro A, Partonen T. Selfreported sleep duration in Finnish general population. J Sleep Res. 2006;15:276-90.

70. Kageyama T, Nishikido N, Kobayashi T, Kawagoe H. Estimated sleep debt and work stress in Japanese white-collar workers. Psychiatry Clin Neurosci. 2001:55(3): 217-9.

71. Härmä M. Kivistö M, Kalimo R, Sallinen M. Work demands, working times and sleep among information technology professionals. In: As times goes by-flexible work hours, health and well-being. Stockholm: SALTSA; 2003. SALTSA report no 8, p 138-53.

72. Åkerstedt $\mathrm{T}$, Knutsson A, Westerholm P, Theorell T, Alfredsson L, Kecklund G. Sleep disturbances, work stress and work hours: a cross-sectional study. J Psychosom Res. 2002;53:741-48.

73. Marmot M. Improvement of social environment to improve health. Lancet. 1998;351:57-60.

74. Hein H, Suadicani P, Gynerberg F. Ischaemic heart disease incidence by social class and form of smoking: the Copenhagen male study: 17 years' follow up. J Intern Med. 1992;231:477-83.

75. Lindfors P, Nurmi K, Meretoja O, Luukkonen R, Viljanen A, Leino T, et al. On-call stress among Finnish anaesthetists. Anaesthesia. 2006;61:856-66.

76. Tenkanen L, Sjöblom T, Härmä M. Joint effect of shift work and adverse life-style factors on the risk of coronary heart disease. Scand J Work Environ Health. 1998;24(5):351-7.

77. Orth-Gomér K. Intervention on coronary risk factors by adapting a shift work schedule to biologic rhythmicity. Psychosom Med. 1983;45:405-15.

78. Knutsson A, Andersson H, Berglund U. Serum lipoproteins in day and shift workers: a prospective study. Br J Ind Med.
$1990 ; 47: 132-4$.

79. Bøggild H, Jeppesen HJ. Intervention in shift scheduling and changes in biomarkers of heart disease in hospital wards. Scand J Work Environ Health. 2001;27(2):87-96.

80. Niedhammer I, Lert F, Marne M. Prevalence of overweight and weight gain in relation to night work in a nurses' cohort. Int J Obes Relat Metab Disord. 1996;20:625-33.

81. Folkard S, Akkerstedt T. A three-process model of the regulation of alertness-sleepiness. In: Broughton R, Ogilvie R, editors. Sleep, arousal, and performance. Boston (MA): Birkhäuser; 1992. p 11-26.

82. Härmä M. Sleepiness and shift work-individual differences. J Sleep Res. 1995;4(2):57-61.

83. Härmä M, Hakola T, Åkerstedt T, Laitinen J. Age and adjustment to night work. Occup Environ Med. 1994;51:568-73.

84. Åkerstedt T, Torsvall L. Shift work: shift-dependent wellbeing and individual differences. Ergonomics. 1981:24;26573.

85. Härmä M, Tenkanen L, Sjöblom R, Alikoski T, Heinsalmi P. Combined effects of shift work and life-style on the prevalence of insomnia, sleep deprivation and daytime sleepiness. Scand J Work Environ Health. 1998;24(4):300-7.

86. Moneta GB, Leclerch A, Chastang J, Tran T, Goldberg M. Time-trend of sleep disorder in relation to night work: a study of sequential 1-year prevalences within the GAZEL cohort. J Clin Epidemiol. 1996;49:1133-41.

87. Härmä, M, Ilmarinen J, Knauth P, Rutenfranz J, Hänninen O. Physical training intervention in female shift workers, II: the effects of intervention on the circadian rhythms of alertness, short-term memory, and body temperature. Ergonomics. 1988;31:51-63.

88. van Amelsvoort L, Schouten E, Maan A, Swenne C, Kok F. Changes in frequency of premature complexes and heart rate variability related to shift work. Occup Environ Med. 2001;58:678-81.

89. Hampton S, Morgan L, Lawrence N, Anastasiodou T, Norris F, Diacon S, et al. Postprandial hormone and metabolic responses in simulated shift work. J Endocrinol. 1996;151(2):259-67.

90. Romon M, Le Fur C, Lebel P, Edmé J-L, Fruchart J-C, Dallongeville J. Circadian variation in postprandial lipemia. Am J Clin Nutr. 1978;65:934-40.

91. Lusardi P, Zoppi A, Preti P, Pesce R, Piazza E, Fogari R. Effects of insufficient sleep on blood pressure in hypertensive patients: a 24-hour study. Am J Hypertens. 1999;12:63-8.

92. Tochikubo O, Ikeda A, Miyajima E, Ishii M. Effects of insufficient sleep on blood pressure monitored by a new multibiomedical recorder. Hypertension. 1996;27:1318-24.

93. Spiegel K, Leproult R, van Cauter E. Impact of sleep debt on metabolic and endocrine function. Lancet. 1999;354:1435-9.

94. Spiegel K, Tasali E, Penev P, van Cauter E. Sleep curtailment in healthy young men is associated with decreased leptin levels, elevated ghrelin levels, and increased hunger and appetite. Ann Intern Med. 2004;141:846-50.

95. Meier-Ewert HK, Rdker PM, Rifai N, Regan M, Price N, Dinges D, et al. Effect of sleep loss on C-reactive protein, and inflammatory marker of cardiovascular risk. J Am Coll Cardiol. 2004;43:678-83.

96. Danesh J, Whincup P, Walker M, Lennon L, Thomson A, Appleby $\mathrm{P}$, et al. Low grade inflammation and coronary heart disease: prospective study and updated meta-analyses. BMJ. 2000;321:199-204.

97. Sluiter JK, Van der Beek AJ, Frings-Dresen MHW. The influence of work characteristics on the need for recovery and 
experienced health: a study on coach drivers. Ergonomics. 1999;42:573-83.

98. Sluiter JK, de Croon EM, Meijman TF, Frings-Dresen MHW. Need for recovery from work related fatigue and its role in the development and prediction of subjective health complaints. Occup Environ Med. 2003;60 suppl 1:62-70.

99. Jansen N, Kant I, van Amelsvoort L, Nijhuis F, van den Brandt P. Need for recovery from work: evaluating short-term effects of work hours, patterns and schedules. Ergonomics. 2003;46(7):664-80.

100. van Amelsvoort LGPM, Jansen NWH, Swaen GMH, van den Brandt PA, Kant I. Direction of shift rotation among threeshift workers in relation to psychological health and workfamily conflict. Scand J Work Environ Health. 2004;30(2):149-56.

101. Kalimo R, Tenkanen L, Härmä M, Poppius E, Heinsalmi P. Job stress and sleep disorders. Findings from the Helsinki Heart Study. Stress Med. 2000;16:65-75.

102. Åkerstedt T, Knutsson A, Westerholm P, Theorell T, Alfredsson L, Kecklund G. Sleep disturbances, work stress and work hours: a cross-sectional study. J Psychosom Res. 2002;53:741-48.

103. Elo A-L, Leppänen A, Jahkola A. Validity of a single-item measure of stress symptoms. Scand J Work Environ Health. 2003;29(6):444-51.

104. Van Amelsvoort LG, Kant IJ, Bultmann U, Swaen GM. Need for recovery after work and the subsequent risk of cardiovascular disease in a working population. Occup Environ Med. 2003;60:83-7.

105. Kivimäki M, Leino-Arjas P, Kaila-Kangas L, Luuukkonen R, Vahtera J, Elovainio M, et al. Is incomplete recover from work a risk marker of cardiovascular death? prospective evidence from industrial employees. Psychosom Med. 2006;68:402-7.

106. Ayas N, White D, Manson J, Stampfer M, Speizer F, Malhotra A, et al. Prospective study of sleep duration and coronary heart disease in women. Arch Intern Med. 2003;163:205-9.

107. Eaker ED, Pinsky J, Castelli WP. Myocardial infarction and coronary death among women: psychosocial predictors from a 20-year follow-up of women in the Framingham study. Am J Epidemiol. 1992;135:854-64.

108. Dinges D, Rogers N, Baynard M. Chronic sleep deprivation. In: Kryger M, Roth T, Dement W, editors. Principles and practice of sleep medicine. Philadelphia (PA): Elsevier Saunders; 2005. p 67-76.

109. Meisinger C, Heier M, Loewel H. Sleep disturbance as a predictor of type 2 diabetes mellitus in men and women from the general population. Diabetelogia. 2005;48:235-41.

110. Nilsson P, Rööst M, Engström G, Hedblad B, Berglund G. Incidence of diabetes in middle-aged men is related to sleep disturbances. Diabetes Care. 2004;27:2464-9.

111. Patel S, Malhotra A, White D, Gottlieg J, Frand B. Association between reduced sleep and weight gain in women. Am J Epidemiol. 2006. [Epub ahead of print]

112. Vahtera J, Pentti J, Helenius H, Kivimäki M. Sleep disturbances as a predictor of long-term increase in sickness absence among employees after family death or illness. Sleep. 2006;29(5):673-82.

113. Smith L, Folkard S, Tucker P, Macdonald I. Work shift duration: a review comparing eight hour and 12 hour shift systems. Occup Environ Med. 1998;55:217-29.

114. Dahlgren A, Kecklund G, Åkerstedt T. Overtime work and its effect on sleep, sleepiness, cortisol and blood pressure in an experimental field study. Scand J Work Environ Health.

\section{6;32(4):318-327.}

115. Wergeland EL, Veiersted B, Ingre M, Olsson B, Åkertedt T, Bjørnskau T, et al. A shorter workday as a means of reducing the occurrence of musculoskeletal disorders. Scand J Work Environ Health. 2003;29(1):27-34.

116. Anttila T. Työajan lyhentäminen ja uudelleenorganisointi [Reduction and reorganization of working time]. Helsinki: Ministry of Labour; 1997. Labour policy studies 171.

117. Åkerstedt T, Olsson b, Ingre M, Holmgren M, Kecklund G. A 6-hour working day-effects on health and well-being. J Human Ergol. 2001;30:197-202.

118. Sallinen M. Can we cope with a shortage of time at work? [editorial]. Scand J Work Environ Health. 2003;29(5):325-7.

119. Taylor W. Transforming work breaks to promote health. Am J Prev Med. 2005;29(5):461-5.

120. Tucker P, Folkard S, Macdonald I. Rest breaks and accident risk. Lancet. 2003;361:680.

121. Ala-Mursula L, Vahtera J, Pentti J, Kivimäki M. Effect of employee worktime control on health: a prospective cohort study. Occup Environ Med. 2004;61:254-61.

122. Ala-Mursula L, Vahtera J, Linna A, Pentti J, Kivimäki M. Employee worktime control moderated the effects of job strain and effort-reward imbalance on sickness a absence: the 10town study. J Epidemiol Community Health. 2005;59:851-7.

123. Kandolin I, Huida O. Individual flexibility: an essential prerequisite in arranging shift schedules for midwives. J Nurs Manag. 1996;4:213-7.

124. Lowden A, Åkerstedt T. Self-selected work hours-work satisfaction, health and social life. In: Hornberger S, Knauth P, Costa G, Folkard S, editors. Shift work in the 21st century: challenges for research and practice. Frankfurt am Main: Peter Lang; 2000. p 345-50. (Arbeitswissenschaft in der betrieblichen Praxis, band 17).

125. Härmä M, Knauth P, Ilmarinen J. Daytime napping and its effects on alertness and short-term memory performance in shift workers. Int Arch Occup Environ Health. 1989;61:3415.

126. Sallinen M, Härmä M, Åkerstedt T, Rosa R, Lillqvist O. Promoting alertness with a short nap during a night shift. J Sleep Res. 1998;7:240-7.

127. Orth-Gomer K. Intervention on coronary risk factors by adapting a shift work schedule to biologic rhythmicity. Psychosom Med. 1983. 45(5):407-15.

128. Knauth P, Hornberger S. Preventive and compensatory measures for shift workers. Occup Med. 2003;53:109-16.

129. Knauth P. Speed and direction of shift rotation. J Sleep Res. 1995;4:41-6.

130. Hakola T, Härmä M. Evaluation of a fast forward rotating shift schedule in the steel industry with a special focus on ageing and sleep. J Hum Ergon 2001;30:35-40.

131. Härmä M, Hakola T, Kandolin I, Sallinen M, Virkkala J, Bonnefond A. A controlled intervention study of the effects of a very rapidly forward rotating shift system on sleep-wakefulness and well-being among young and elderly shift workers. Int J Psychophysiol. 2006:59;70-9.

132. Czeisler C, Moore-Ede M, Coleman R. Rotating shift work schedules that disrupt sleep are improved by applying circadian principles. Science. 1982;217(4558):460-3.

133. Härmä MI, Ilmarinen JE. Towards the 24-hour society-new approaches for aging shift workers? Scand J Work Environ Health. 1999;25(6, special issue):610-15.

134. Härmä M. Circadian adaptation to shift work: a review. In: Hornberger S, Knauth P, Costa G , Folkard S, editors. Shiftwork in the 21st century. Frankfurt am Main: Peter Lang: 
2000. p 125-30. (Arbeitswissenschaft in der betrieblichen Praxis, Bd.17. p. 125-30)

135. Koller M, Härmä M, Laitinen J, Kundi M, Haider M. Combined effects of night work and light on circadian functions. Arch Complex Environ Stud. 1993;5:37-46.

136. Folkard S, Tucker P. Shift work, safety and productivity. Occup Med. 2003;53:95-01.
137. Costa G, Ghilranda G, Arondi G, Minors D, Waterhouse J. Evaluation of a rapidly rotating shift system for tolerance of nurses to nightwork. Int Arch Occup Environ Health. 1994;65:305-11.

Received for publication: 24 March 2006 